\title{
PROMETHEUS - SISTEMA COMPUTACIONAL INTEGRADO DE CONTROLE DE INCÊNDIOS FLORESTAIS
}

\author{
José Renato Soares Nunes*, Ronaldo Viana Soares**, Antônio Carlos Batista*** \\ *Eng. Florestal, Dr., Pós-doutorando em Ciências Florestais, UFPR - zerenato@floresta.ufpr.br \\ **Eng. Florestal, Ph.D., Depto. de Ciências Florestais, UFPR - rvsoares@ufpr.br \\ ***Eng. Florestal, Dr., Depto. de Ciências Florestais, UFPR - batistaufpr@ufpr.br \\ Recebido para publicação: 07/03/2007 - Aceito para publicação: 07/05/2007
}

\begin{abstract}
Resumo
O objetivo deste trabalho foi desenvolver um sistema computacional utilizando a modelagem funcional, que permita calcular o índice de perigo de incêndios florestais pela Fórmula de Monte Alegre (FMA) e Fórmula de Monte Alegre Alterada $\left(\mathrm{FMA}^{+}\right)$original, Ajuste 1 e Ajuste 2, e armazenar informações referentes às ocorrências de incêndios florestais. $\mathrm{O}$ sistema possibilita a geração de estatísticas sobre índices de perigo e incidência de incêndios, a partir do Diagrama de Contexto, dos Diagramas de Fluxo de Dados de Nível 1 e de Nível 2 e do Diagrama de EntidadeRelacionamento. O sistema Prometheus foi desenvolvido usando a linguagem Borland Delphi 6.0 com acesso via Borland Database Engine (BDE) e base de dados Paradox.

Palavras-chave: Sistema de incêndios florestais; banco de dados de incêndios florestais; proteção florestal.
\end{abstract}

\begin{abstract}
Prometheus - integrated wildfire control computational system. The main objectives of this paper were to develop a computational system, using the functional modeling, that allows to calculate the forest fire danger index through the Monte Alegre Formula (FMA) and the original, adjusted 1 and adjusted 2 Modified Monte Alegre Formula $\left(\mathrm{FMA}^{+}\right)$and to store information of forest fire occurrence. The system also permits the generation of danger indices and forest fire occurrence statistics from the Context Diagram, the Level 1 and Level 2 Data-Flow Diagrams, and the EntityRelationship. The Prometheus system was developed using the Borland Delphi 6.0 language with Borland Database Engine (BDE) access and Paradox database.

Keywords: Wildfire system; wildfire data base; forest protection.
\end{abstract}

\section{INTRODUÇÃO}

A utilização de um índice de perigo confiável é fator fundamental para um planejamento mais eficiente das atividades de prevenção e para a adoção de ações rápidas e efetivas nas atividades de combate aos incêndios florestais, visando à redução das perdas e, conseqüentemente, dos prejuízos financeiros advindos da ocorrência de eventos catastróficos.

Os índices de perigo utilizam informações meteorológicas e climatológicas e a qualidade desses dados é vital para o planejamento de prevenção e combate aos incêndios florestais (SOARES, 1984; BATISTA, 1990). A ocorrência e propagação dos incêndios florestais estão fortemente associadas às condições climáticas ou fatores climáticos. A intensidade de um incêndio e a velocidade com que ele avança está diretamente ligada à umidade relativa, precipitação, temperatura do ar e velocidade do vento (CHENEY, 1968; SCHROEDER; BUCK, 1970; HEIKKILÄ et al., 1993).

No Brasil, a falta de informações integradas em âmbito nacional ou mesmo regional e a falta de ferramentas computacionais são alguns dos sérios problemas para os técnicos que atuam na prevenção e combate aos incêndios florestais. Algumas empresas têm dificuldade em operacionalizar suas atividades de prevenção aos incêndios florestais por falta de uma ferramenta que os auxilie nos cálculos dos índices de perigo ao longo do tempo. A falta de monitoramento e de adoção de políticas preventivas e de combate aos incêndios florestais em determinados biomas e unidades de conservação tem causado prejuízos incalculáveis à biodiversidade.

O objetivo deste trabalho foi desenvolver um sistema computacional a partir da modelagem 
funcional (YOURDON, 1992; GANE; SARSON, 1995; POMPILHO, 1995) e da modelagem de dados (SILBERSCHATZ et al., 1999; DATE, 2000), visando calcular e armazenar o índice de perigo de incêndios florestais calculado pela Fórmula de Monte Alegre - FMA (SOARES, 1972a; SOARES, 1972b) e pela Fórmula de Monte Alegre Alterada - $\mathrm{FMA}^{+}$(NUNES, 2005) para uma região, mantendo uma base de dados com a evolução diária desses índices. O sistema visa armazenar a ocorrência de incêndios florestais, permitindo a geração de estatísticas sobre os índices de perigo e a ocorrência desse tipo de incêndio. Outras funcionalidades foram incorporadas na especificação, como a correção da umidade relativa e o cálculo da umidade relativa a partir das temperaturas obtidas de um psicrômetro.

\section{MATERIAL E MÉTODOS}

\section{Modelagem funcional}

O Sistema Integrado de Controle de Incêndios Florestais (Prometheus) foi desenvolvido a partir da modelagem funcional (YOURDON, 1992; GANE; SARSON, 1995; POMPILHO, 1995) e da modelagem de dados (SILBERSCHATZ et al., 1999; DATE, 2000), cujas especificações são apresentadas a seguir. Os diagramas de Contexto e de Fluxo de Dados definem os principais processos que fazem parte do sistema.

\section{Diagrama de contexto}

O sistema recebe como entrada dados meteorológicos e dados sobre a ocorrência de incêndios florestais, produzindo informações sobre o perigo de incêndios e estatísticas dos incêndios, o que auxilia na tomada de decisões sobre o controle dos incêndios florestais (Figura 1).

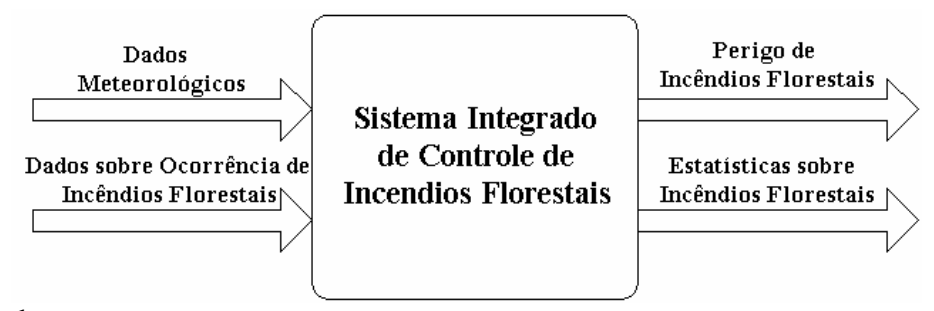

Figura 1. Diagrama de contexto.

Figure 1. Context diagram.

\section{Diagrama de fluxo de dados nível 1}

No primeiro nível de detalhamento, o sistema foi dividido em dois processos distintos, como apresentado na figura 2: o processo Determinação de Índices de Perigo de Incêndios Florestais e o processo de Atualização da Base de Incêndios Florestais.

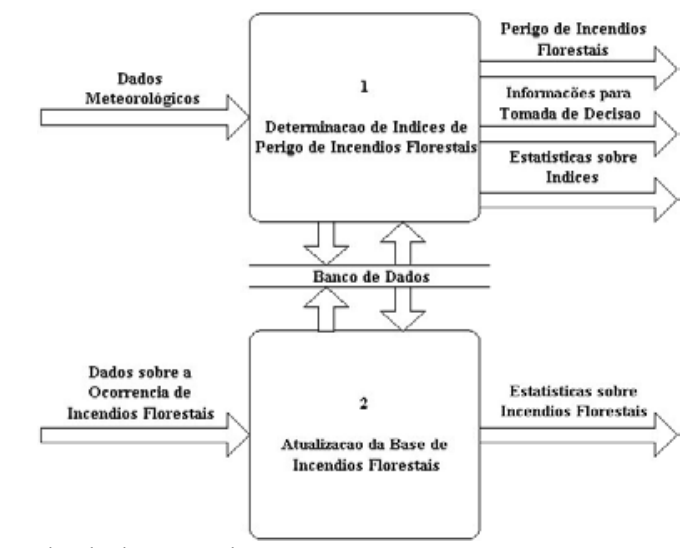

Figura 2. Diagrama de fluxo de dados nível 1.

Figure 2. Level 1 data-flow diagram. 


\section{Diagrama de fluxo de dados nível 2}

No segundo nível de detalhamento, os principais processos que farão parte do sistema foram definidos e divididos em dois grupos: Determinação de Inndices de Perigo de Incêndios Florestais e Atualização da Base de Incêndios Florestais. As figuras 3 e 4 apresentam os diagramas de fluxo de dados desses dois grupos.

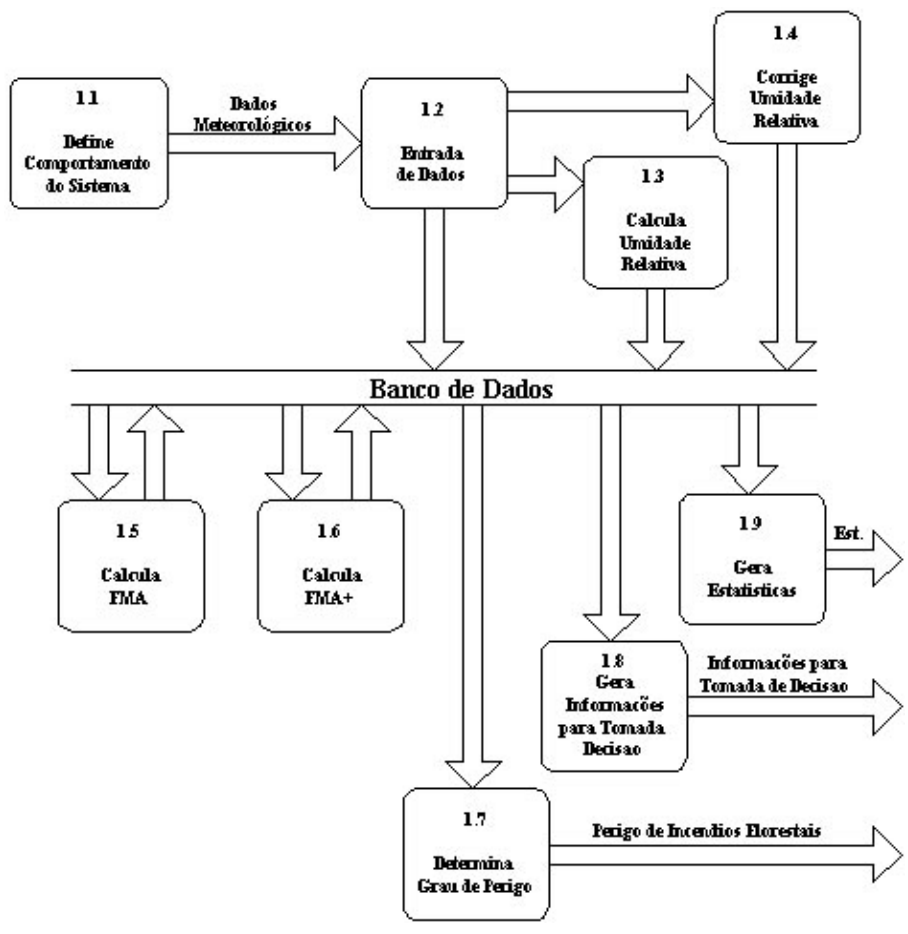

Figura 3. Diagrama de fluxo de dados nível 2: determinação de índices de perigo de incêndios florestais. Figure 3. Level 2 data-flow diagram: fire danger index determination.

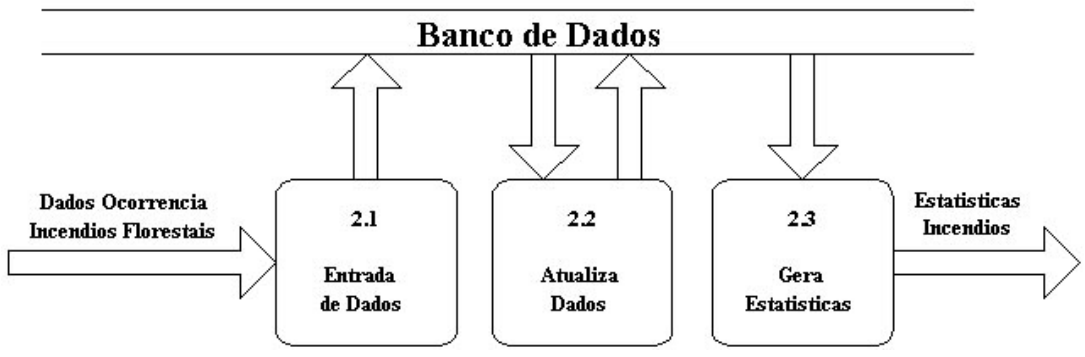

Figura 4. Diagrama de fluxo de dados nível 2: atualização da base de incêndios florestais.

Figure 4. Level 2 data-flow diagram: wildfire database update.

\section{Modelagem de dados}

A maioria dos bancos de dados segue um modelo relacional, que se caracteriza por uma coleção de tabelas, cada qual designada por um nome único. Todo sistema de banco de dados deve apresentar um projeto, que visa a organização das informações e utilização de técnicas para que o futuro sistema obtenha bom desempenho e também facilite as manutenções necessárias. O projeto de banco de dados se dá em duas fases: a modelagem conceitual e o projeto lógico. 


\section{O modelo conceitual}

O diagrama de Entidade-Relacionamento define a estrutura de dados que faz parte do sistema (Figura 5). O modelo apresenta em sua estrutura a capacidade de armazenar dados meteorológicos, através da entidade Dados_Clima, índices de perigo de incêndios florestais, através da entidade Índice_Perigo, e dados sobre a ocorrência de incêndios florestais, através da entidade Ocorrência.

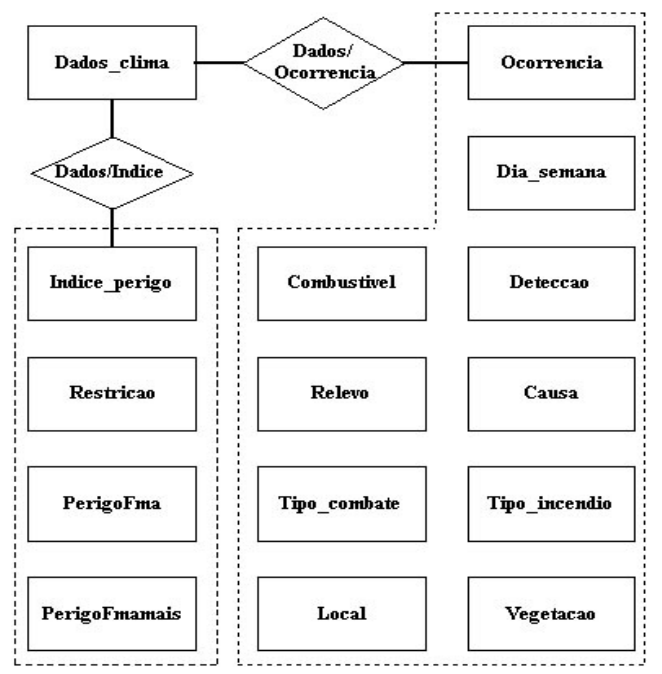

Figura 5. Diagrama de Entidade-Relacionamento.

Figure 5. Entity-Relationship Diagram.

\section{O modelo lógico}

Na especificação do Modelo Lógico, foi feita a descrição de todas as tabelas referentes aos dados meteorológicos, aos índices de perigo de incêndios e às ocorrências de incêndios florestais. Para algumas tabelas auxiliares foram definidas as opções para preenchimento dos campos, com o objetivo de padronizar as informações.

Descrição das tabelas referentes aos dados meteorológicos e índices de perigo de incêndios florestais Dados_clima (data, local, altitude, umidade_relativa_13, precipitação_diária, velocidade_vento_13) Operações: inclusão, alteração, exclusão.

Índice_perigo (data, local, acumulado, PerigoFma, grau_perigo, valor_fmamais, PerigoFmamais) Operações: valores calculados a partir da tabela de clima, exportação de dados.

Restrição (lim_inferior, lim_superior, dedução)

PerigoFma (código, val_inferior, val_superior, grau_perigo)

PerigoFmamais (código, val_inferior, val_superior, grau_perigo)

\section{Descrição das tabelas referentes à ocorrência de incêndios florestais}

Ocorrência (data, local, dia semana, latitude, longitude, hora detecção, hora incêndio_controlado, hora_incêndio_extinto, informante, área_queimada, detecção, causa, tipo_incêndio, vegetação, combustível, relevo, tipo_combate)

Operações: inclusão, alteração, exclusão.

Dia_semana (código, dia)

Opções de Dia_semana: domingo, segunda-feira, terça-feira, quarta-feira, quinta-feira, sexta-feira, sábado. 
Detecção (código, forma detecção)

Opções de Detecção: vigilante móvel, vigilante fixo, vizinho, torre, avião, satélite, outros.

Causa (código, causa)

Opções de Causa: raios, incendiários, queimas_para_limpeza, fumantes, recreação, estradas_de_ferro, operações_florestais, diversos.

Tipo_incêndio (código, tipo_incêndio)

Opções de Tipo de incêndio: subterrâneo, superficial, copa.

Vegetação (código, tipo_vegetação)

Opções de Vegetação: nativa, exótica.

Combustível (código, tipo_combustível)

Opções de Combustível: pasto, cerrado, agricultura, capoeira, campo, floresta nativa, pinus, eucalipto, araucária, outras florestas plantadas.

Relevo (código, tipo_terreno)

Opções de Relevo: plano, ondulado, medianamente ondulado, fortemente ondulado.

Tipo_combate (código, tipo_combate)

Opções de Tipo de combate: ataque direto, ataque pelos flancos, contra-fogo, apoio aéreo, apoio terrestre.

\section{Base teórica para os principais algoritmos}

Cálculo da Umidade Relativa

Para o cálculo da umidade relativa a partir das temperaturas dos bulbos úmido e seco do psicrômetro e da altitude, foram utilizadas as seguintes fórmulas (SOARES; BATISTA, 2004):

a) Cálculo da pressão atmosférica:

$\mathrm{P}_{\mathrm{z}}=760(1-0,0065 \mathrm{z} / 288)^{5,2568}$

onde: $\quad P_{z}=$ pressão atmosférica em uma dada altitude em mmHg

$\mathrm{z}=$ altitude em metros

b) Determinação da pressão máxima de vapor d'água:

$\mathrm{E}_{\mathrm{T}}=4,58 \times 10^{(7,5 \mathrm{~T} / 237,3+\mathrm{T})}$

onde: $\quad \mathrm{E}_{\mathrm{T}}=$ pressão máxima de vapor d'água na temperatura $\mathrm{T}$, em $\mathrm{mmHg}$

$\mathrm{T}=$ temperatura do $\operatorname{ar} \mathrm{em}^{\circ} \mathrm{C}$

c) Determinação da pressão máxima de vapor para a temperatura do bulbo úmido, em $\mathrm{mmHg}$ :

$\mathrm{E}^{\prime}=4,58 \times 10^{\left(7,5 \mathrm{~T}^{\prime} / 237,3+\mathrm{T}^{\prime}\right)}$

onde: $\quad E^{\prime}=$ pressão máxima de vapor d'água na temperatura T' (bulbo úmido), em mmHg

$\mathrm{T}^{\prime}=$ temperatura do bulbo úmido $\mathrm{em}^{\circ} \mathrm{C}$

d) Determinação da pressão real de vapor:

$\mathrm{e}=\mathrm{E}^{\prime}-\mathrm{CP}_{\mathrm{z}}\left(\mathrm{T}-\mathrm{T}^{\prime}\right)$

onde: $\quad \mathrm{e}=$ pressão real de vapor, $\mathrm{em} \mathrm{mmHg}$

$\mathrm{E}^{\prime}=$ pressão máxima de vapor d'água para a temperatura T'

$\mathrm{C}=$ constante psicrométrica: $\mathrm{C}=0,0008$ sem ventilação forçada; $\mathrm{C}=0,0006$ com ventilação

$\mathrm{P}_{\mathrm{z}}=$ pressão atmosférica $\mathrm{em} \mathrm{mmHg}$

$\mathrm{T}=$ temperatura do ar (bulbo seco) em ${ }^{\circ} \mathrm{C}$

$\mathrm{T}^{\prime}=$ temperatura do bulbo úmido $\mathrm{em}{ }^{\circ} \mathrm{C}$ 
e) Determinação da Umidade Relativa:

$\mathrm{UR}=(\mathrm{e} / \mathrm{ET}) .100$

\section{Correção da umidade relativa}

Segundo Nunes (2005), a estimativa da umidade relativa diária das 13:00 h, válida para o estado do Paraná, pode ser obtida através da leitura das umidades relativas das 9:00 ou das 15:00 h, através das seguintes equações:

$$
\begin{aligned}
& \mathrm{UR}_{13}=e^{\left(2,72976+0,0162192 \mathrm{UR}_{09}\right)} \\
& \mathrm{UR}_{13}=2,451510 \mathrm{UR}_{15}^{0,796072}
\end{aligned}
$$

\section{Cálculo de FMA}

A equação básica da Fórmula de Monte Alegre é a seguinte (SOARES, 1972b):

$$
\mathrm{FMA}=\sum_{\mathrm{i}=1}^{\mathrm{n}}\left(100 / \mathrm{H}_{\mathrm{i}}\right)
$$

onde: $\quad$ FMA $=$ Fórmula de Monte Alegre

$\mathrm{H}=$ umidade relativa do ar $(\%)$, medida às $13: 00 \mathrm{~h}$

$\mathrm{n}=$ número de dias sem chuva maior ou igual a $13,0 \mathrm{~mm}$

Por ser acumulativo, o índice está sujeito às restrições de precipitação, como mostra a tabela 1.

Tabela 1. Restrições da Fórmula de Monte Alegre em função da quantidade de chuva do dia.

Table 1. Restrictions to the daily FMA summation according to the precipitation.

\begin{tabular}{ll}
\hline Chuva do dia (mm) & \multicolumn{1}{c}{ Modificação no cálculo } \\
\hline$\leq 2,4$ & Nenhuma \\
2,5 a 4,9 & Abater 30\% na FMA calculada na véspera e somar $(100 / \mathrm{H})$ do dia. \\
5,0 a 9,9 & Abater $60 \%$ na FMA calculada na véspera e somar $(100 / \mathrm{H})$ do dia. \\
10,0 a 12,9 & Abater $80 \%$ na FMA calculada na véspera e somar $(100 / \mathrm{H})$ do dia. \\
$>12,9$ & Interromper o cálculo (FMA $=0)$ e recomeçar o somatório no dia seguinte ou \\
& quando a precipitação for menor ou igual a 2,4. \\
\hline
\end{tabular}

A interpretação do grau de perigo estimado pela Fórmula de Monte Alegre é feita por meio da escala apresentada na tabela 2 .

Tabela 2. Escala de perigo da Fórmula de Monte Alegre.

Table 2. Forest fire danger scale for the FMA.

\begin{tabular}{lc}
\hline Valor de FMA & Grau de perigo \\
\hline$\leq 1,0$ & Nulo \\
1,1 a 3,0 & Pequeno \\
3,1 a 8,0 & Médio \\
8,1 a 20,0 & Alto \\
$>20,0$ & Muito alto \\
\hline
\end{tabular}

$\mathrm{FMA}^{+}$Original

A Fórmula de Monte Alegre Alterada - $\mathrm{FMA}^{+}$(NUNES, 2005), que inclui a velocidade do vento, tem a seguinte representação:

$$
\mathrm{FMA}^{+}=\sum_{\mathrm{i}=1}^{\mathrm{n}}\left(100 / \mathrm{H}_{\mathrm{i}}\right) \mathrm{e}^{0,04 \mathrm{v}}
$$


onde: $\quad \mathrm{FMA}^{+}=$Fórmula de Monte Alegre Alterada

$\mathrm{H}=$ umidade relativa do ar em porcentagem, medida às 13:00 $\mathrm{h}$

$\mathrm{n}=$ número de dias sem chuva maior ou igual a $13,0 \mathrm{~mm}$

$\mathrm{v}=$ velocidade do vento em $\mathrm{m} / \mathrm{s}$, medida às 13:00 $\mathrm{h}$

$\mathrm{e}=$ base dos logaritmos naturais $(2,718282)$

Por ser acumulativo, o índice está sujeito às mesmas restrições de precipitação apresentadas na tabela 1. A interpretação do grau de perigo estimado pela $\mathrm{FMA}^{+}$é feita através da escala apresentada na tabela 3 .

Tabela 3. Escala de perigo da $\mathrm{FMA}^{+}$.

Table 3. Forest fire danger scale for the $\mathrm{FMA}^{+}$.

\begin{tabular}{lc}
\hline Valor de FMA $^{+}$ & Grau de perigo \\
\hline$\leq 3,0$ & Nulo \\
3,1 a 8,0 & Pequeno \\
8,1 a 14,0 & Médio \\
14,1 a 24,0 & Alto \\
$>24,0$ & Muito alto \\
\hline
\end{tabular}

\section{FMA $^{+}$ajuste 1}

A equação para o cálculo do índice e as restrições referentes à precipitação são as mesmas da $\mathrm{FMA}^{+}$original. A única alteração foi feita na interpretação do grau de perigo (Tabela 4).

Tabela 4. Escala de Perigo - $\mathrm{FMA}^{+}$Ajuste 1.

Table 4. Fire danger scale for the $\mathrm{FMA}^{+}$adjust 1.

\begin{tabular}{lc}
\hline Valor de FMA $^{+}$ & Grau de perigo \\
\hline$\leq 4,0$ & Nulo \\
4,1 a 9,0 & Pequeno \\
9,1 a 16,0 & Médio \\
16,1 a 30,0 & Alto \\
$>30,0$ & Muito alto \\
\hline
\end{tabular}

\section{$\mathrm{FMA}^{+}$ajuste 2}

No ajuste 2 também a única alteração foi feita na escala do grau de perigo (Tabela 5).

Tabela 5. Escala de Perigo - $\mathrm{FMA}^{+}$ajuste 2 .

Table 5. Fire danger scale for the $\mathrm{FMA}^{+}$adjust 2.

\begin{tabular}{lc}
\hline${\text { Valor de } \text { FMA }^{+}}^{+}$ & Grau de perigo \\
\hline$\leq 5,0$ & Nulo \\
5,1 a 12,0 & Pequeno \\
12,1 a 21,0 & Médio \\
21,1 a 35,0 & Alto \\
$>35,0$ & Muito alto \\
\hline
\end{tabular}

\section{RESULTADOS E DISCUSSÃO}

Prometheus é um sistema computacional que permite calcular e armazenar, realizar consultas, emitir relatórios e gráficos do índice de perigo de incêndios florestais determinado pela FMA e FMA $\mathrm{FMa}^{+}$ versão Original, Ajuste 1 e Ajuste 2. Permite também armazenar, realizar consultas e emitir relatórios de informações referentes aos incêndios florestais. Outras funcionalidades foram incorporadas ao sistema, como a correção da umidade relativa das 9:00 h e das 15:00 h para as 13:00 h e o cálculo da umidade relativa a partir das temperaturas do psicrômetro e da altitude do local.

O sistema foi desenvolvido em um ambiente que proporcionasse fácil utilização e entendimento 
por parte do usuário, sem deixar de lado as questões de segurança e confiabilidade. Várias opções referentes ao cálculo e ajuste de umidade relativa foram incluídas, tornando o sistema bastante flexível, podendo ser configurado para a realidade do usuário.

Consultas, exportação de partes da base de dados para formatos .doc, .xls e .rtf, relatórios, gráficos e um módulo de auxílio à tomada de decisão dão ao usuário o suporte necessário ao manejo do fogo em sua empresa ou unidade de conservação. Procedimentos de geração e restauração de cópia de segurança são responsáveis por garantir a integridade do sistema, preservando os dados do usuário.

\section{Principais funções do sistema}

As principais funções do sistema são: Configuração do Sistema, Gerar Cópia de Segurança, Restaurar Cópia de Segurança, Cadastramento de Usuários, Cadastramento e Consulta de Índices de Perigo, Cadastramento e Consulta de Ocorrência de Incêndios Florestais, Emissão de Relatórios, Visualização de Gráficos e um módulo de Auxílio à Tomada de Decisão. A figura 6 apresenta a janela inicial do sistema.

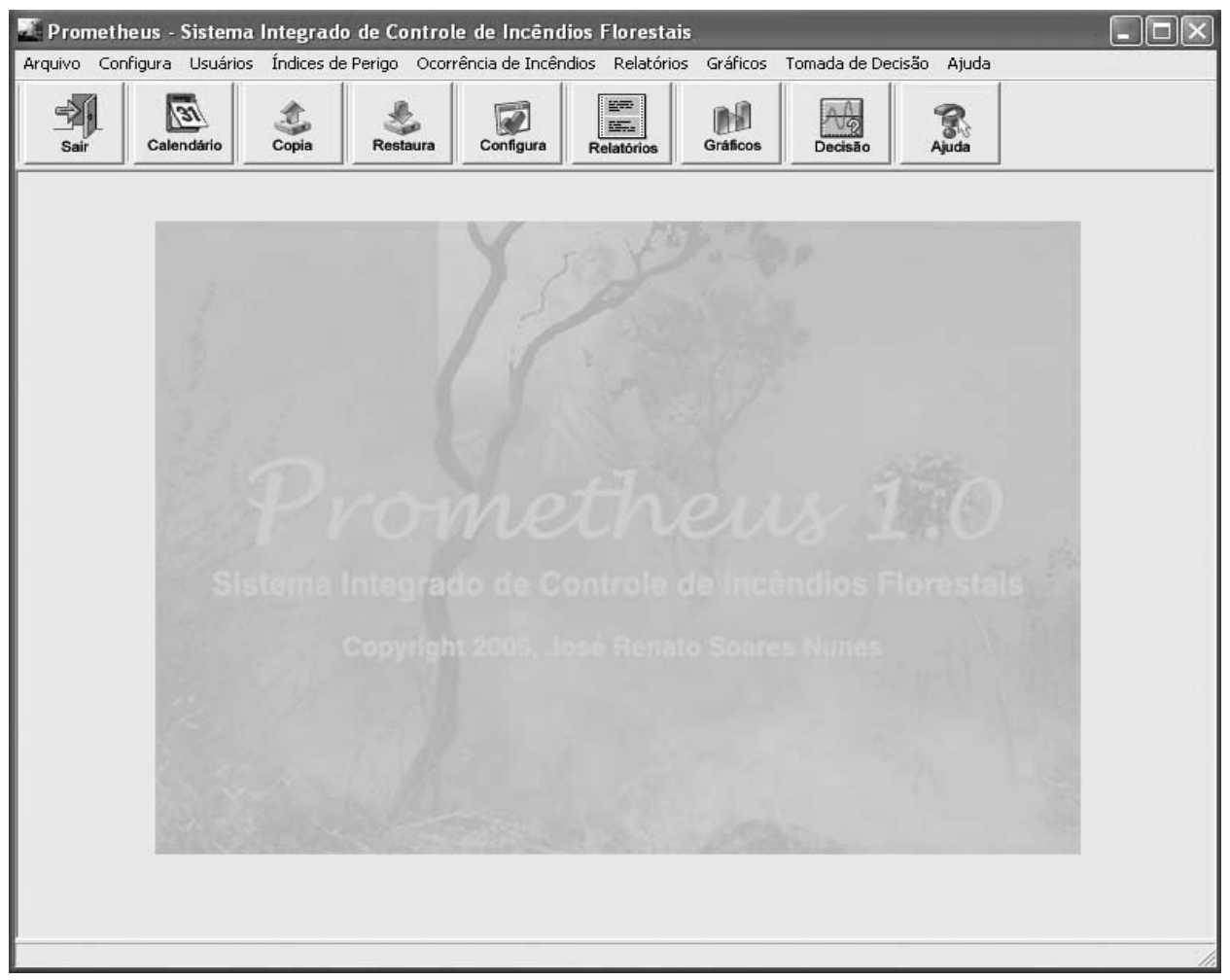

Figura 6. Janela inicial do sistema Prometheus.

Figure 6. Prometheus system main window.

\section{Configuração do sistema}

A opção Configuração é a primeira tarefa que o usuário deve realizar antes de colocar o sistema em funcionamento. Depois de se certificar do tipo de índice a ser usado e dos valores de umidade relativa existentes, deve-se realizar a configuração que vai definir o comportamento do sistema, habilitando e desabilitando opções. A figura 7 apresenta a janela de configuração do sistema.

A configuração se refere somente à opção Índice de Perigo e não interfere na opção Ocorrência de Incêndios, que é deixada habilitada. É importante que o usuário registre as ocorrências de incêndio, pois esses dados são importantes para futura análise de desempenho do índice de perigo na região e para a realização de ajustes ao índice, quando necessário.

A primeira opção permite ao usuário escolher entre usar a $\mathrm{FMA}$ ou a $\mathrm{FMA}^{+}$. O usuário pode 
utilizar $\mathrm{FMA}^{+}$somente se tiver, além dos dados da umidade relativa das 13:00 h e da precipitação diária, a velocidade do vento às 13:00 h. $\mathrm{A} \mathrm{FMA}^{+}$foi ajustada e validada para três regiões do estado do Paraná. A opção padrão é a FMA.

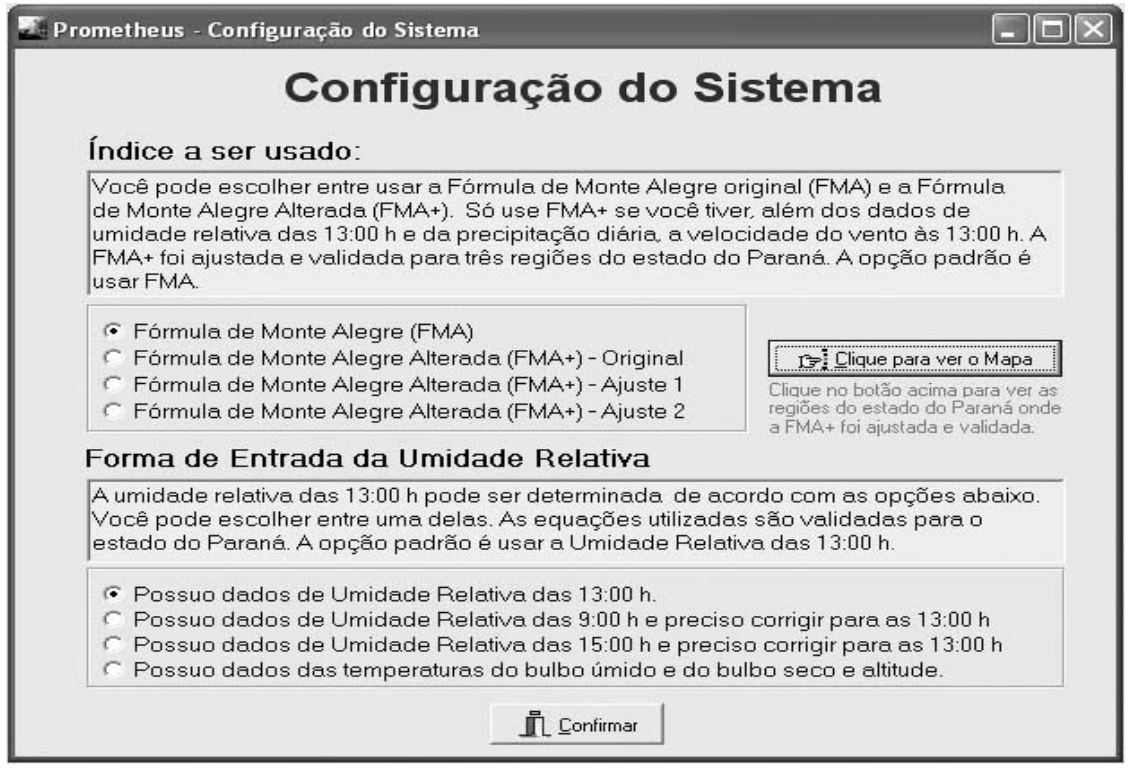

Figura 7. Configuração do Sistema.

Figure 7. System configuration.

A segunda opção permite ao usuário escolher a forma de entrada da umidade relativa. Uma das opções apresentadas deve ser selecionada. As equações utilizadas foram validadas para o estado do Paraná. A opção padrão é a Umidade Relativa das 13:00 h.

\section{Cópia de Segurança}

A questão da segurança dos dados é contemplada pelo sistema Prometheus de forma a deixar o usuário em uma situação confortável em relação aos dados, desde que ele adote uma estratégia com o objetivo de se proteger contra eventos indesejáveis.

Existem duas funções básicas: Gerar Cópia de Segurança e Restaurar Cópia de Segurança. O usuário pode Gerar Cópia de Segurança a qualquer momento que desejar. Quando o usuário aciona essa função em Arquivo/Gerar Cópia de Segurança, é gravada uma cópia de todos os dados existentes no banco de dados naquele instante em um diretório, como, por exemplo, c: IIncendios $\backslash$ Dados15-8-2006 2306-06, que identifica a data e a hora em que a cópia foi gerada. Esse aspecto facilita uma futura recuperação dos dados. Sugere-se que periodicamente esses dados sejam gravados em uma mídia externa ao computador, como $\mathrm{CD}$ ou pen drive.

Para Restaurar Cópia de Segurança, existem duas possibilidades. A primeira se refere à recuperação de dados em função de alguma operação equivocada do usuário, como apagar registros que não deveriam ser apagados. Nesse caso, o usuário pode restaurar a última cópia de segurança, bastando, para isso, entrar na opção Arquivo/Restaurar Cópia de Segurança.

A segunda possibilidade refere-se a problemas mais sérios de corrupção da base de dados. Nesse caso, o usuário deve realizar a recuperação externamente, pois o sistema apresenta erro na base de dados e não inicia. Para realizar a restauração, deve ser executado o programa restaura.exe que se encontra no diretório c:IIncendios e apresenta as mesmas características da versão interna. Quando se instala o sistema, é gerado um ícone na área de trabalho do usuário chamado Restaurar Cópia de Segurança, que permite a execução externa do programa de restauração.

Em ambos os casos será apresentada uma janela que permite ao usuário selecionar a versão de cópia desejada. Normalmente a versão mais recente é a escolhida. A figura 8 apresenta a janela para restauração da cópia de segurança. 


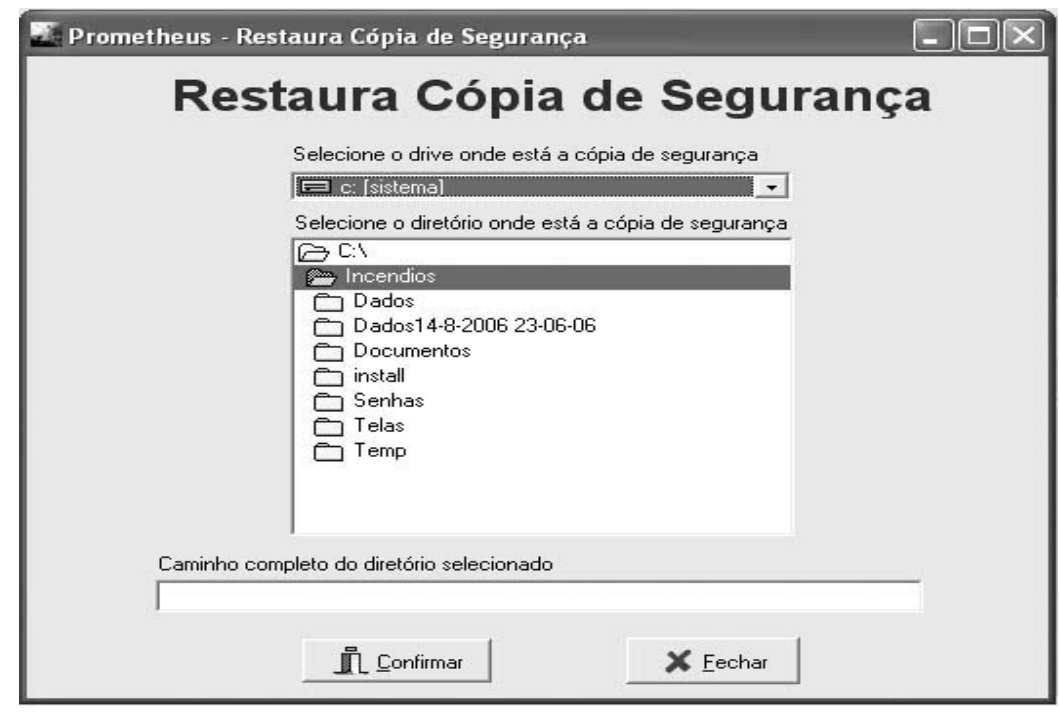

Figura 8. Janela para restauração da cópia de segurança.

Figure 8. Security copy recover window.

\section{Usuários}

A opção Usuários permite o cadastramento de novos usuários e a troca do usuário ativo sem a necessidade de sair do sistema (Figura 9).

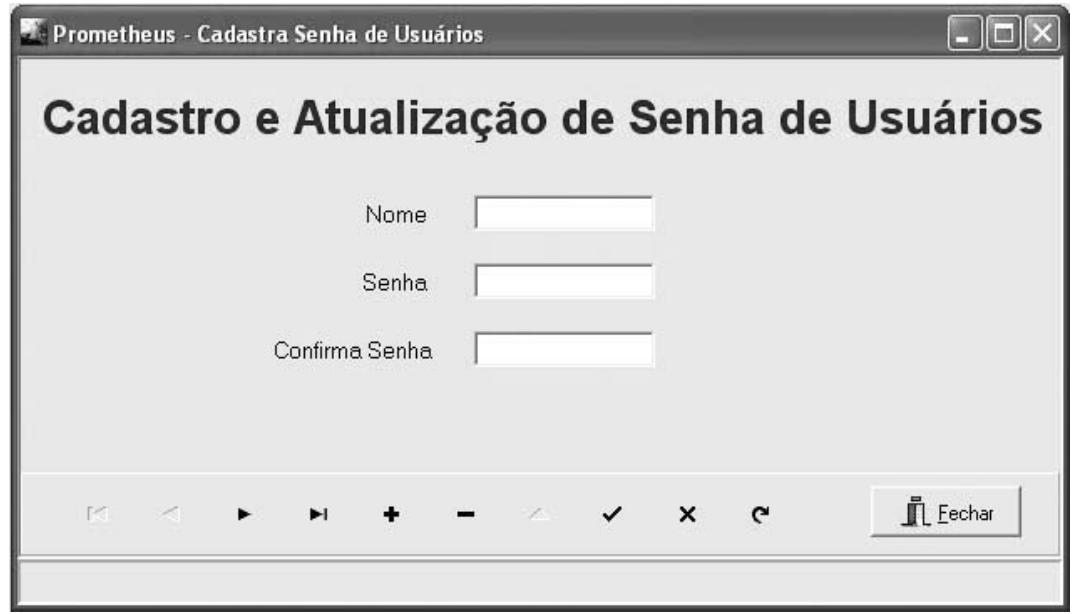

Figura 9. Janela de cadastramento de usuários.

Figure 9. User registration window.

O sistema só pode ser utilizado por usuários autorizados. Para tanto, eles devem ser cadastrados para posterior acesso, podendo-se incluir, alterar e excluir nomes e senhas de usuários. O único usuário que não pode ser excluído, alterado ou ter a senha modificada é o usuário admin, que já existe quando o sistema é instalado. O usuário admin é o único que tem permissão para criar novos usuários e alterar suas características, como nome e senha.

\section{Índices de perigo}

A opção Índices de Perigo permite calcular, armazenar e consultar o índice de perigo de incêndios florestais diário, calculado pela FMA e pela $\mathrm{FMA}^{+}$original, Ajuste 1 e Ajuste 2 .

As três versões da $\mathrm{FMA}^{+}$se referem a ajustes realizados para o estado do Paraná. Caso o local onde o usuário irá utilizar o sistema seja em outro estado, sugere-se a adoção da $\mathrm{FMA}^{+}$original e depois 
de um ano de uso diário, juntamente com o registro das ocorrências de incêndios florestais na região, $o$ índice poderá ter o seu desempenho avaliado e, se necessário, ajustado para a região.

\section{Fórmula de Monte Alegre}

Um dos principais pontos positivos da FMA é a sua simplicidade, pois utiliza apenas duas variáveis meteorológicas de fácil obtenção, umidade relativa do ar e precipitação. A figura 10 apresenta a janela de cadastramento para FMA, e a figura 11, a janela para consulta de FMA.

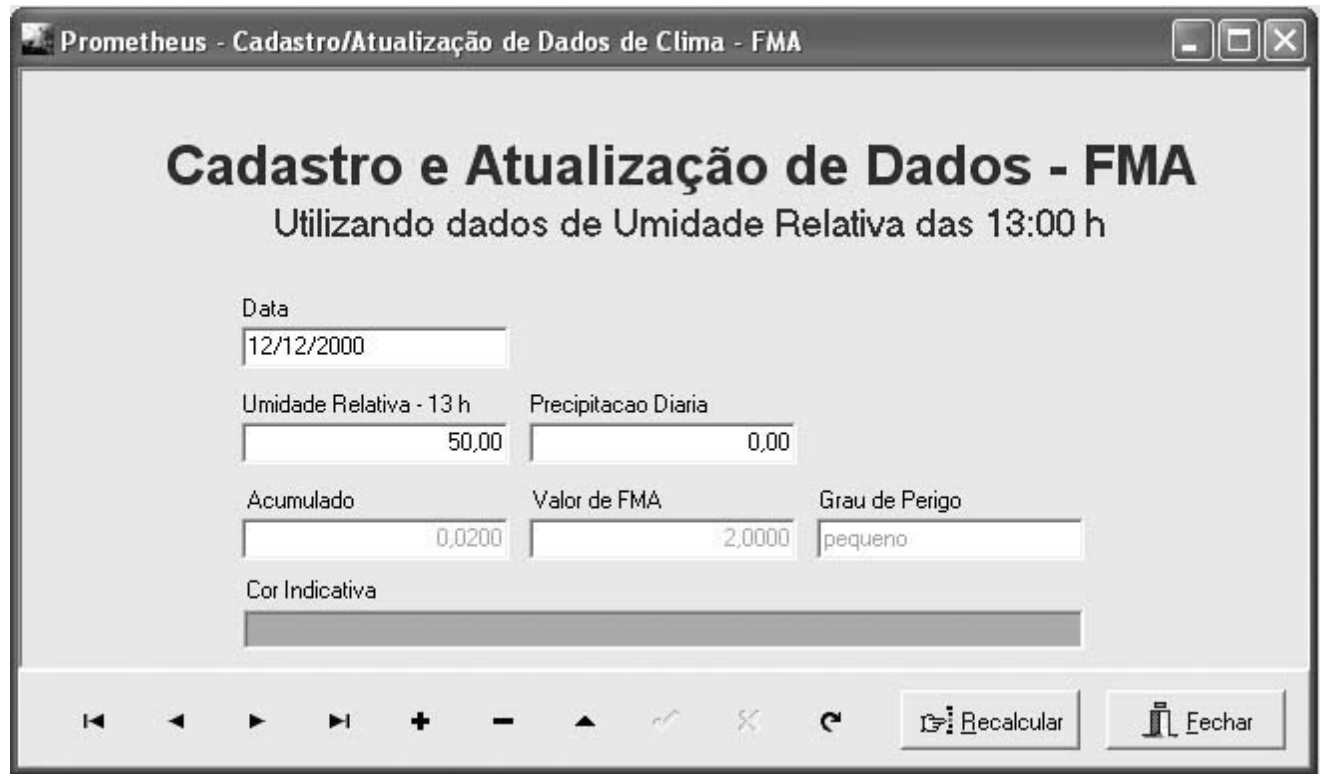

Figura 10. Cadastro de FMA.

Figure 10. FMA calculation.

\begin{tabular}{|c|c|c|c|c|c|c|c|c|c|}
\hline \multicolumn{7}{|c|}{ L Prometheus - Consulta - FMA } & \multicolumn{3}{|c|}{$-\square x$} \\
\hline \multicolumn{10}{|l|}{ Data } \\
\hline Data Inicial & $1 / 6 / 1998$ & $\div$ & Data Final & \multicolumn{2}{|c|}{$23 / 6 / 1998$} & $\div$ & DF Procurar & & \\
\hline Data & Umidade Relativa & $-13 \mathrm{~h}$ & Precipitação & o Diária & Acumulado & Valor de FMA & Grau de Perigo & & $\widehat{\wedge}$ \\
\hline 01/06/1998 & & 67,00 & & 0,00 & 0,0149 & \begin{tabular}{l|l}
9 & 1,4925 \\
\end{tabular} & \begin{tabular}{|l|l}
5 & pequeno
\end{tabular} & & \\
\hline $02 / 06 / 1998$ & & 60.70 & & 0.00 & 0,0314 & 3,1400 & médio & & \\
\hline $03 / 06 / 1998$ & & 63,40 & & 0,00 & 0,0472 & 4,7173 & médio & & \\
\hline 04/06/1998 & & 61,70 & & 0,00 & 0,0634 & 6,3380 & médio & & \\
\hline 05/06/1998 & & 51,70 & & 0,00 & 0,0827 & 8,2723 & alto & & \\
\hline $06 / 06 / 1998$ & & 60,20 & & 0,00 & 0,0993 & 9.9334 & alto & & \\
\hline $07 / 06 / 1998$ & & 60,70 & & 0,00 & 0,1158 & 11.5808 & alto & & \\
\hline $08 / 06 / 1998$ & & 56,50 & & 0,00 & 0.1335 & 13,3507 & alto & & \\
\hline \multirow[t]{2}{*}{$09 / 06 / 1998$} & & 57,30 & & 0,00 & 0,1510 & 15,0959 & alto & & \multirow{2}{*}{$\underline{v}$} \\
\hline & s & - & $\rightarrow$ & & \multicolumn{2}{|c|}{$\Rightarrow$ Exportar } & 员 Eecha & & \\
\hline
\end{tabular}

Figura 11. Consulta aos valores da FMA.

Figure 11. FMA values review. 


\section{Fórmula de Monte Alegre Alterada}

Desenvolvida por Nunes (2005) para a Região Central do estado do Paraná, município de Telêmaco Borba, a $\mathrm{FMA}^{+}$foi ajustada para o estado do Paraná e apresenta três escalas de perigo distintas. A figura 12 apresenta as regiões do estado do Paraná nas quais devem ser adotadas essas escalas.

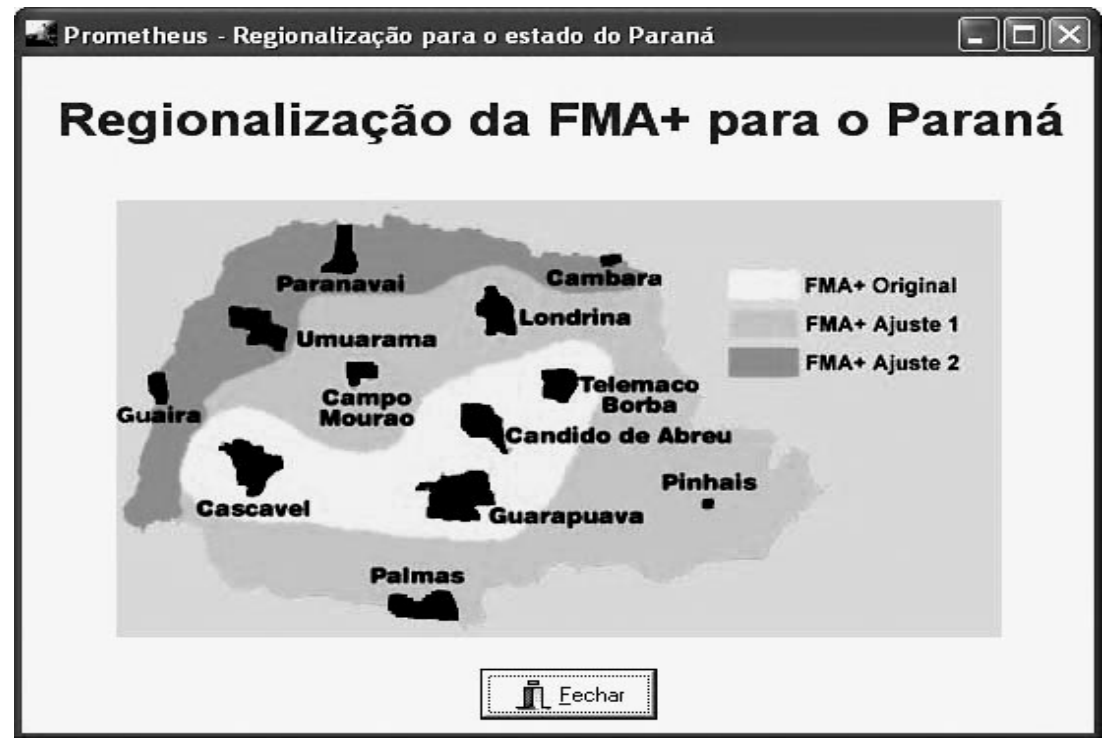

Figura 12. Regiões com escalas de perigo semelhantes.

Figure 12. Similar fire danger scale regions for the $\mathrm{FMA}^{+}$in the Paraná State.

A escala de perigo original deve ser utilizada na área central do estado, onde se encontram as regiões de Cândido de Abreu, Cascavel, Guarapuava e Telêmaco Borba. A escala de perigo denominada "Ajuste 2" deve ser utilizada no extremo norte do estado, compreendendo as regiões de Cambará, Guaíra, Paranavaí e Umuarama. Finalmente, a escala de perigo denominada "Ajuste 1" deve ser utilizada para o restante do estado, validada pelas regiões de Campo Mourão, Londrina, Palmas e Pinhais.

\section{FMA $^{+}$Original, FMA $^{+}$Ajuste 1 e FMA ${ }^{+}$Ajuste 2}

As janelas de $\mathrm{FMA}^{+}$Original, $\mathrm{FMA}^{+}$Ajuste 1 e $\mathrm{FMA}^{+}$Ajuste 2 são semelhantes. Para fins de ilustração, serão apresentadas somente as janelas da FMA ${ }^{+}$Original (Figuras 13 e 14).

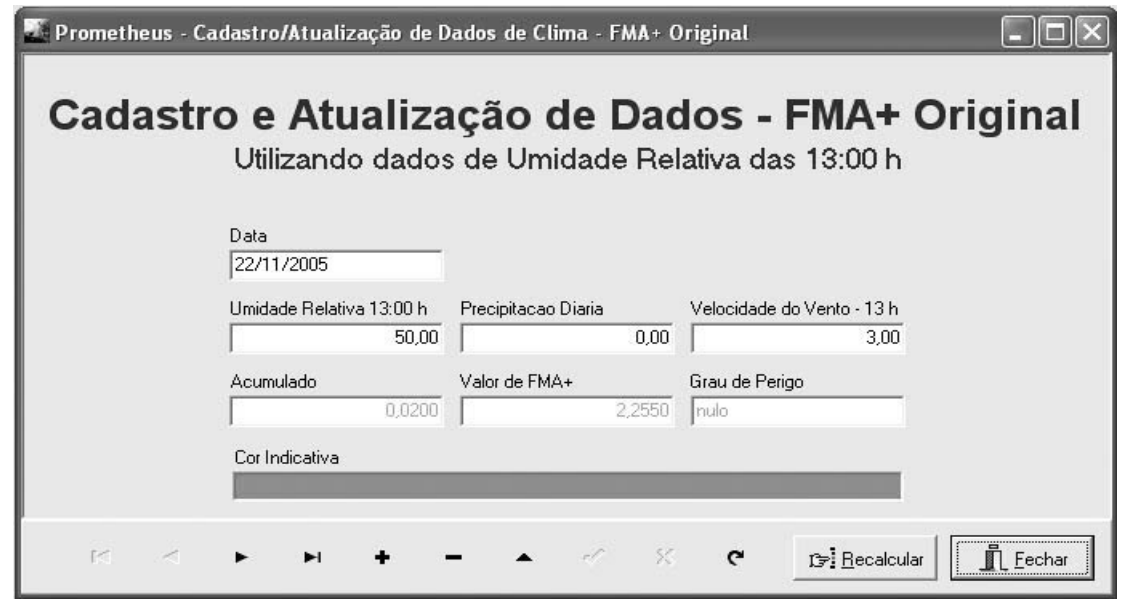

Figura 13. Cadastro de $\mathrm{FMA}^{+}$Original.

Figure 13. Original $\mathrm{FMA}^{+}$calculation. 


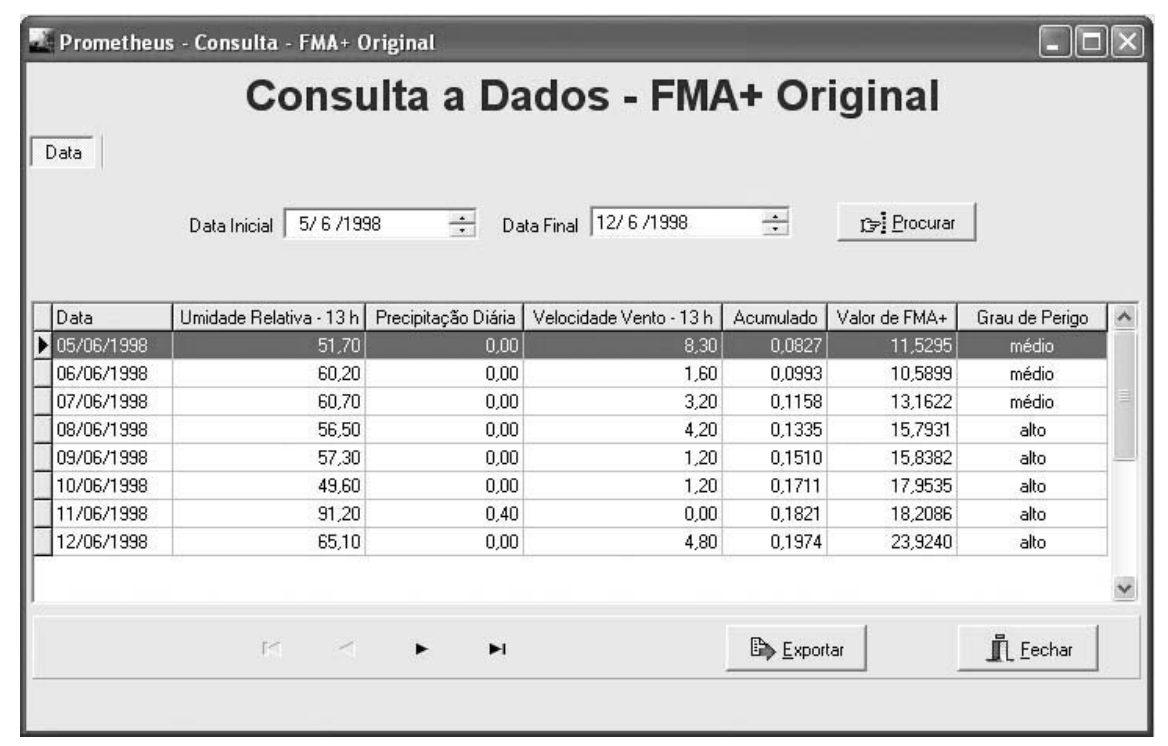

Figura 14. Consulta $\mathrm{FMA}^{+}$Original.

Figure 14. Original $\mathrm{FMA}^{+}$review.

\section{Correção da umidade relativa}

Outra funcionalidade importante é a correção da umidade relativa das 9:00 e das 15:00 horas para as 13:00 horas, quando não se tem este valor disponível. A figura 15 apresenta, como exemplo, a janela de cadastramento para $\mathrm{FMA}^{+}$Original quando se vai usar a correção da umidade relativa das 9:00 para as 13:00 horas.

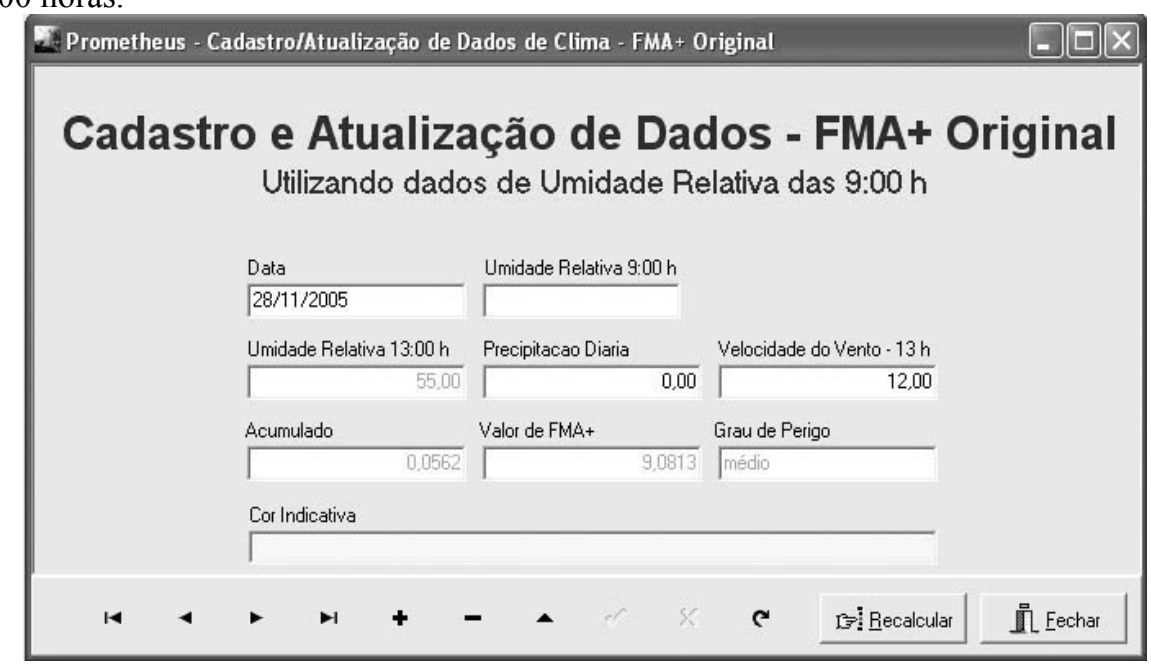

Figura 15. Cadastro com correção da umidade relativa das 9:00 para as 13:00 h.

Figure 15. Original $\mathrm{FMA}^{+}$calculation with relative humidity correction from $9 \mathrm{AM}$ to $1 \mathrm{PM}$.

\section{Cálculo da umidade relativa}

Outra função também contemplada pelo sistema é o cálculo da umidade relativa através das temperaturas do psicrômetro e da altitude do local (Figura 16). Vale ressaltar que os dados de temperatura do bulbo seco, do bulbo úmido e da altitude não são armazenados na base de dados. Somente a umidade relativa calculada será gravada. 


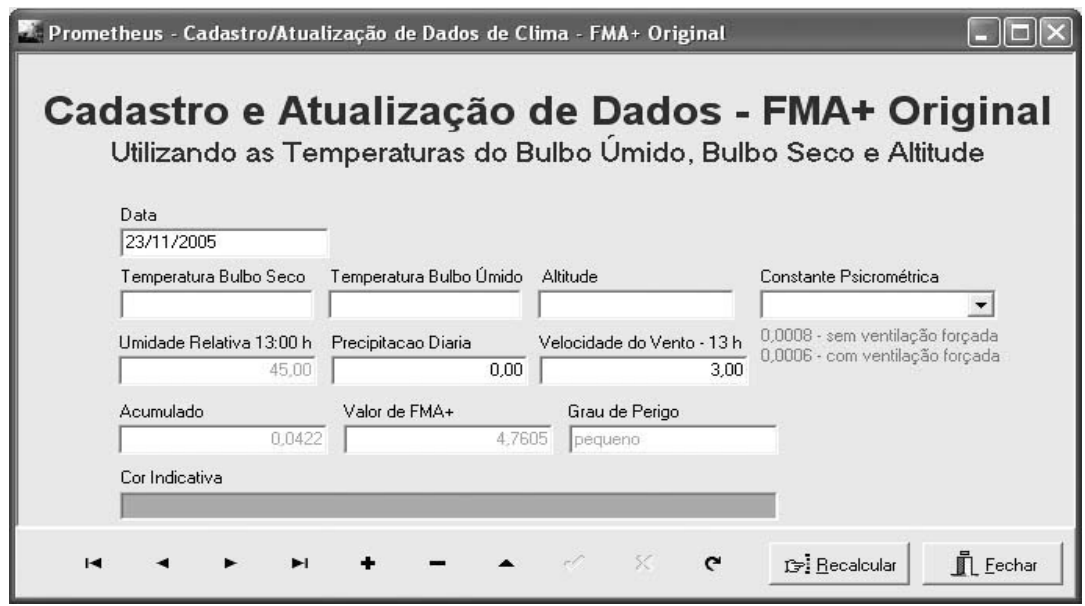

Figura 16. Cadastro com cálculo da umidade relativa.

Figure 16. Original $\mathrm{FMA}^{+}$calculation with relative humidity determination.

\section{Ocorrência de incêndios}

A opção Ocorrência de Incêndios permite cadastrar e consultar informações referentes à ocorrência de incêndios em uma localidade, município e estado, divididas em três grupos: Informações Gerais, Caracterização da Área e Caracterização do Incêndio.

Todas as informações são obrigatórias durante o cadastramento. Essa decisão de desenvolvimento foi tomada com o objetivo de evitar que sejam criadas bases de dados incompletas das ocorrências.

As consultas podem ser feitas por data, localidade, município, estado, dia da semana, causa do incêndio, vegetação e combustível (Figuras 17 e 18).

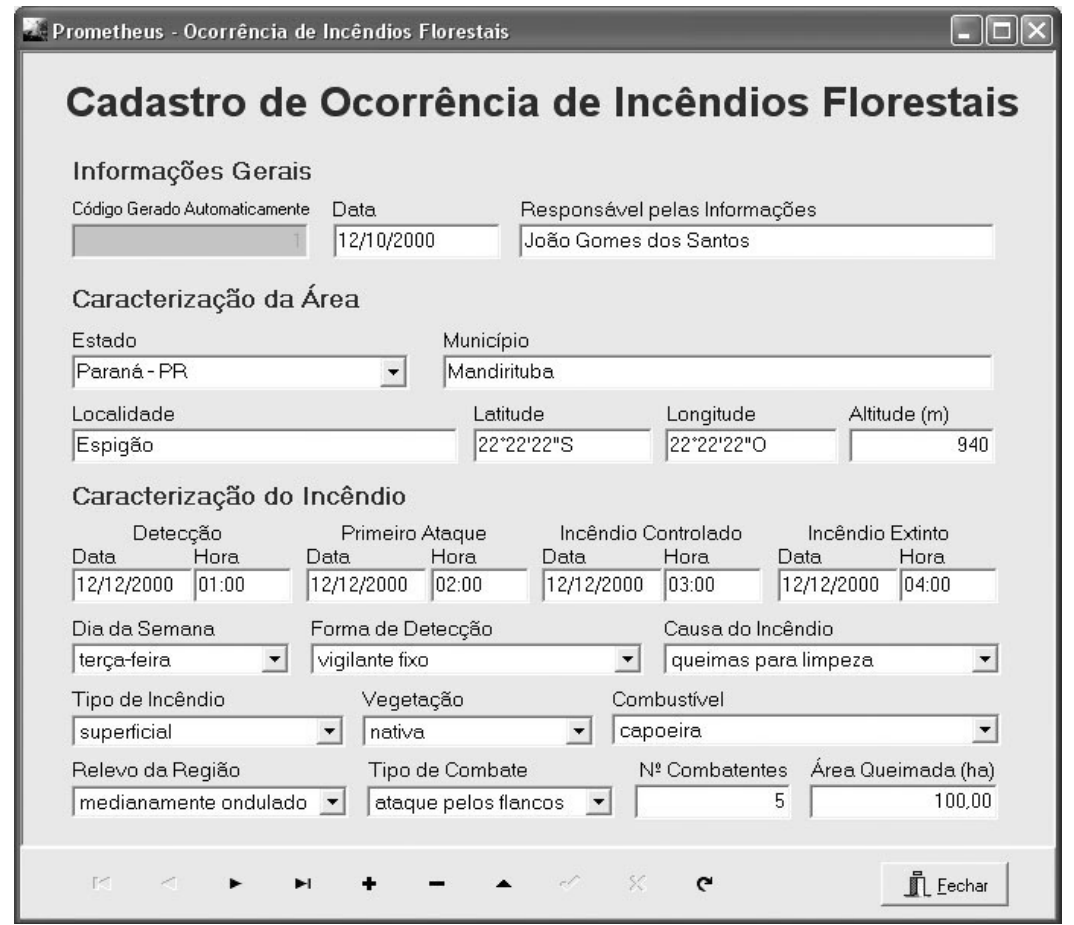

Figura 17. Cadastramento de ocorrências de incêndios florestais.

Figure 17. Forest fire occurrence recording. 


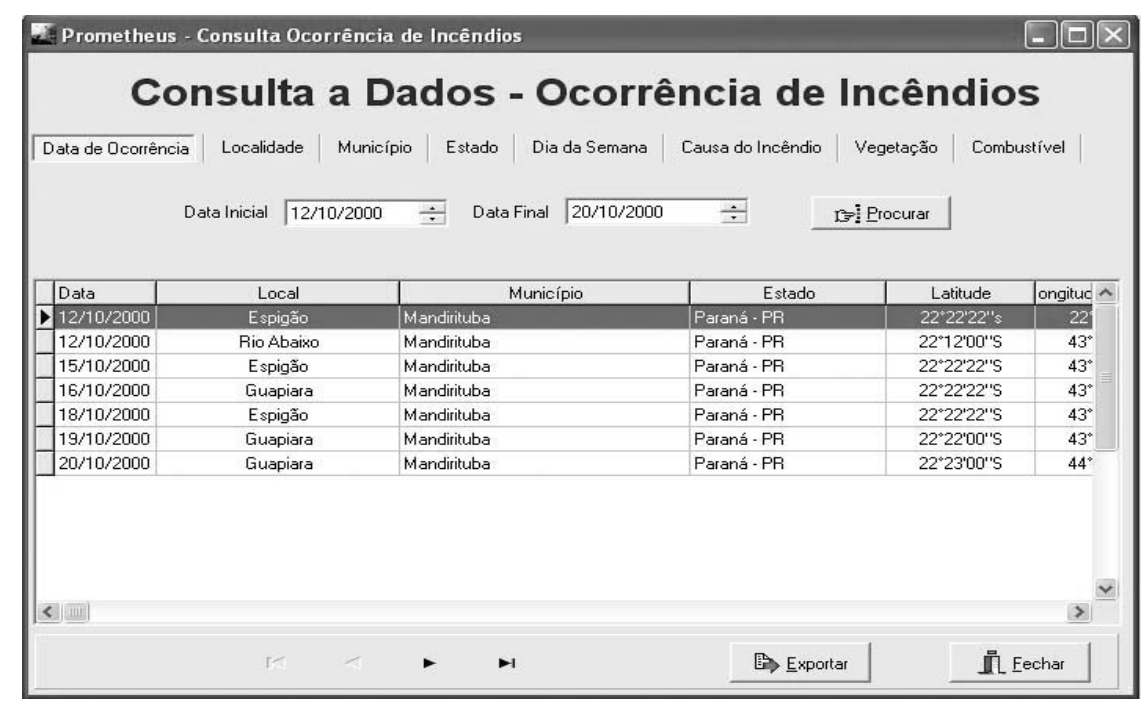

Figura 18. Consulta de ocorrências de incêndios florestais.

Figure 18. Forest fire occurrence review.

Na janela de Consulta a Dados de Ocorrência de Incêndios, existe também um botão chamado Exportar, cuja função é exportar a consulta realizada para os formatos Excel, HTML e área de transferência. Essa opção permite tanto exportar para um arquivo no diretório c: $\backslash$ Incendios $\backslash$ Exporta como visualizar o arquivo na opção escolhida. Nesse caso, em função do tamanho da tabela, foram retiradas as opções para exportar para Word-doc e RTF. Essa facilidade é um recurso para a geração de relatórios a partir de seleções feitas sobre a base de dados.

\section{Relatórios}

A opção Relatórios deve ser utilizada para a visualização textual e impressão de relatórios, tanto da base de índices de perigo quanto da base de ocorrência de incêndios. A figura 19 ilustra a janela de seleção do relatório, permitindo a sua visualização na tela ou a sua impressão. Convém ressaltar que em função da configuração feita pelo usuário, só estará habilitada a sua opção.

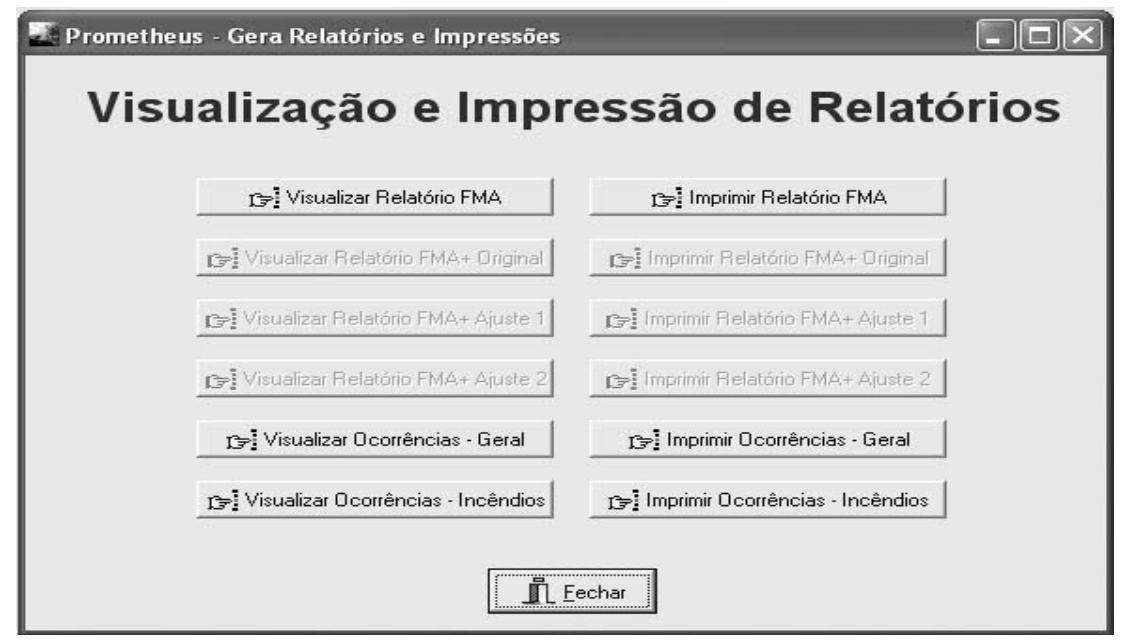

Figura 19. Janela de visualização de relatórios e impressão.

Figure 19. Report generation and printing visualization window. 


\section{Gráficos}

A opção Gráficos deve ser utilizada para a visualização gráfica das variáveis que foram utilizadas para o cálculo do índice escolhido, como a umidade relativa, a precipitação, o vento, quando for o caso, e do valor do índice escolhido. A figura 20 apresenta o gráfico dos valores da $\mathrm{FMA}^{+}$Original.

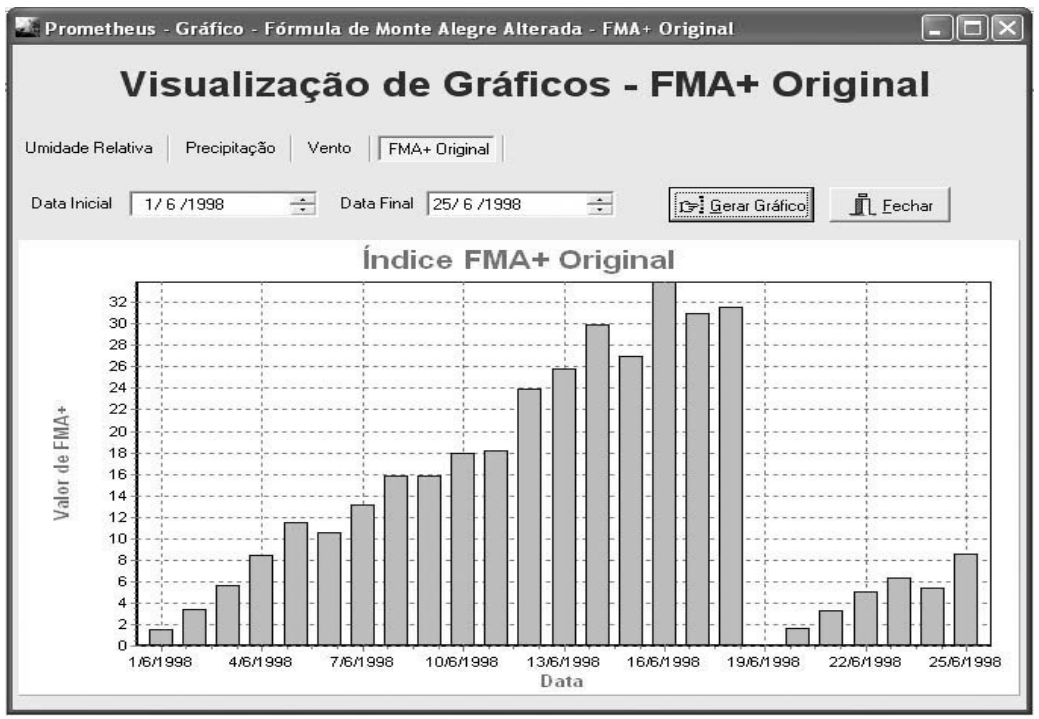

Figura 20. Visualização de gráfico de $\mathrm{FMA}^{+}$Original.

Figure 20. Original $\mathrm{FMA}^{+}$graphic visualization.

\section{Auxílio à tomada de decisão}

A opção Auxílio à Tomada de Decisão tem a função de contribuir para que o usuário tenha uma idéia de que decisões devem ser tomadas em relação à evolução do grau de perigo ao longo do tempo.

As informações sobre as Medidas Preventivas a serem tomadas, o Comportamento do Fogo e as Dificuldades de Supressão do Fogo, para cada grau de perigo, dão ao usuário um suporte aos principais problemas que podem ser enfrentados para o manejo do fogo. A figura 21 apresenta a janela de auxílio à tomada de decisão.

\begin{tabular}{|c|c|}
\hline \multicolumn{2}{|c|}{ E Prometheus - Auxilio à Tomada de Decisão } \\
\hline \multicolumn{2}{|c|}{$\begin{array}{l}\text { Auxílio à Tomada de Decisão } \\
\text { Grau de Perigo Medidas Preventivas }\end{array}$} \\
\hline $\begin{array}{l}\ulcorner\text { Nulo } \\
\curvearrowright \text { Pequeno } \\
\curvearrowright \text { Médio } \\
\curvearrowright \text { Alto } \\
\odot \text { Muito Alto }\end{array}$ & $\begin{array}{l}\text { O perigo de incêndios é muito alto. Os meios de controle como equipes de combate, } \\
\text { ferramentas, equipamentos de proteção individual, demais equipamentos e veículos e } \\
\text { sistema de comunicação estão em condições de serem usados A vigilância preventiva } \\
\text { deve ser intensificada, aumentando o período de operação das torres e de vigilância } \\
\text { móvel. A passagem por áreas críticas será muito limitada não se permitindo o uso do } \\
\text { fogo nas proximidades dessas áreas. As operaçóes agrícolas e florestais que usam } \\
\text { fogo devem ser suspensas. A populaçâo e entidades de proteçâap devem ser avisadas } \\
\text { por veículos de comunicaçâo como rádio e televisão para que tome medidas } \\
\text { preventivas. Equipe (s) de primeiro combate devem ficar de plantão para qualquer } \\
\text { eventualidade. }\end{array}$ \\
\hline Cor Indicativa & Comportamento do Fogo \\
\hline & $\begin{array}{l}\text { A ignição é imediata e o fogo se propaga extremamente rápido, com fagulhamento à } \\
\text { longa distância nesses tipos de combustiveis. O comprimento das chamas fica entre } 5,0 \\
\text { e } 15 \text { metros ou mais. A taxa de propagaçấo na frente do fogo pode ser superior a } 4,0 \\
\text { quilômetros por hora. }\end{array}$ \\
\hline & Dificuldade de Supressão do Fogo \\
\hline & $\begin{array}{l}\text { Qualquer forma de combate fica impossibilitado até que as condições meteorológicas } \\
\text { mudem. O uso de contra-fogo é perigoso e deve ser evitado. }\end{array}$ \\
\hline & 题 Eechar \\
\hline
\end{tabular}

Figura 21. Janela de auxílio à tomada de decisão.

Figure 21. Decision making window based on the fire danger. 


\section{Observações gerais}

Em todas as janelas de Cadastramento e Atualização de Dados referentes aos índices existe um botão chamado Recalcular, cuja função é muito importante. Determinadas operações, como exclusão, alteração e inclusão fora da seqüência de tempo normal, podem fazer com que a base de dados fique em um estado inconsistente, pois, como os índices são acumulativos, qualquer alteração na seqüência normal dos dados pode deixar os valores incorretos. Para as operações de exclusão e alteração, o sistema já recalcula os dados automaticamente. Para inclusões fora da seqüência de tempo normal, é necessário comandar a operação para recalcular os valores do índice, bastando, para tal, acionar o referido botão. A operação de inclusão normal não tem problema e o sistema processa os dados normalmente. A execução de uma operação de recálculo sem que haja necessidade não traz qualquer problema para a base.

\section{CONCLUSÕES}

O sistema Prometheus foi desenvolvido para a plataforma Windows XP, tendo como princípio de desenvolvimento oferecer uma interface simples ao usuário.

Testes do sistema na plataforma Windows 98 funcionaram normalmente, o que possibilita a sua instalação nesse ambiente.

A preocupação com a segurança do sistema e a integridade das informações permite ao usuário a proteção de seus dados e a recuperação deles em casos de eventos catastróficos, desde que sejam adotadas políticas de retirada de cópias de segurança.

\section{REFERÊNCIAS}

BATISTA, A. C. Incêndios florestais. Recife: UFRPE, 1990. 115 p.

CHENEY, N. P. Predicting fire behavior with fire danger tables. Australian Forestry, Canberra, v. 32, n. 2, p. 71-79, 1968.

DATE, C. J. Introdução a sistemas de bancos de dados. 7. ed. Rio de Janeiro: Campus, 2000.

GANE, C.; SARSON, T. Análise estruturada de sistemas. 18. ed. Rio de Janeiro: Livros Técnicos e Científicos, $1995.257 \mathrm{p}$.

HEIKKILÄ, T. V.; GRONOVIST, R.; JURVÉLIUS, M. Handbook on forest fire control. Helsinki: Forestry Training Programme, 1993. 239 p. (Publication, n. 21).

NUNES, J. R. S. FMA ${ }^{+}$- Um novo índice de perigo de incêndios florestais para o estado do Paraná Brasil. 150 f. (Doutorado em Engenharia Florestal) - Setor de Ciências Agrárias, Universidade Federal do Paraná, Curitiba, 2005.

NUNES, J. R. S.; SOARES, R. V.; BATISTA, A. C. Ajuste da Fórmula de Monte Alegre Alterada FMA $^{+}$para o estado do Paraná. Revista Floresta, Curitiba, v.37, n,1, p. 1-14, 2007.

POMPILHO, S. Análise Essencial: guia prático de análise de sistemas. Rio de Janeiro: IBPI, 1995.

SCHROEDER, M. J.; BUCK, C. C. Fire weather. Washington, DC: USDA Forest Service, 1970. 229 p. (Agriculture Handbook, n. 360).

SILBERSCHATZ, A.; KORTH, H.; SUDARSHAN, S. Sistema de bancos de dados. 3. ed. São Paulo: Makron Books, 1999.

SOARES, R. V. Índices de perigo de incêndio. Revista Floresta, Curitiba, v. 3, n. 3, p. 19-40, 1972.

SOARES, R. V. Determinação de um índice de perigo de incêndio para a região centro paranaense, Brasil. 72 f.. Tese (Mestrado) - Instituto Interamericano de Cięncias Agrícolas da OEA. Departamento de Cięncias Florestais/Centro Tropical de Ensino e Investigação, Turrialba, 1972b.

SOARES, R. V. Prevenção e controle de incêndios florestais. Brasília, DF: ABEAS, 1984. 120 p. 
SOARES, R. V. Incêndios florestais: controle e uso do fogo. Curitiba: Fundação de Pesquisas Florestais do Paraná, 1985. 213 p.

SOARES, R. V.; BATISTA, A. C. Meteorologia e Climatologia Florestal. Curitiba: UFPR / Centro de Ciências Florestais e da Madeira, 2004. 195 p.

YOURDON, E. Análise estruturada moderna. Rio de Janeiro: Campus, 1992. 